\title{
Analysis of Response Evaluation Criteria in Solid Tumors reduction ratio of primary chemotherapy in unresectable advanced or recurrent colorectal cancer
}

\author{
SHIHO KAWAGOE ${ }^{1}$, MASAHIRO NAKANO ${ }^{2}$, KEITA UCHINO ${ }^{1}$, KOHEI ARIMIZU ${ }^{1}$, TATSUHIRO KAJTTANI ${ }^{1}$, \\ HOZUMI SHIMOKAWA $^{1}$, TETSUYA KUSUMOTO ${ }^{3}$, KOJI IKEJIRI ${ }^{3}$ and EISHI BABA ${ }^{4}$ \\ ${ }^{1}$ Department of Medical Oncology, Clinical Research Institute, National Hospital Organization Kyushu Medical Center, \\ Fukuoka, Fukuoka 810-8563; ${ }^{2}$ Department of Nursing, Faculty of Health Sciences, Junshin Gakuen University, Fukuoka, \\ Fukuoka 815-0036; ${ }^{3}$ Department of Gastrointestinal Surgery, National Hospital Organization Kyushu Medical Center, \\ Fukuoka, Fukuoka 810-8563; ${ }^{4}$ Department of Comprehensive Clinical Oncology, Faculty of Medical Sciences, \\ Kyushu University, Fukuoka, Fukuoka 812-8582, Japan
}

Received September 13, 2018; Accepted June 14, 2019

DOI: $10.3892 / \mathrm{mco} .2019 .1894$

\begin{abstract}
Response Evaluation Criteria in Solid Tumors (RECIST) is used to assess the objective response of solid tumors to treatment. However, it remains unclear to what extent the response rate assessed by RECIST reflects a reduction of tumor size in multiple organs in patients with unresectable advanced or recurrent colorectal cancer (CRC) with multiple organ metastases. It is also unclear whether the management of liver metastases with systemic chemotherapy in CRC patients with multiple organ metastases improves their prognosis, although surgical resection has been shown to be the most effective treatment approach to CRC cases with liver metastases. A total of 38 CRC patients who underwent systemic chemotherapy in Kyushu Medical Center Hospital between January 2013 and April 2016 were examined. The patients had measurable lesions in multiple organs, including the liver, and did not undergo curative surgery for metastatic lesions after initiation of chemotherapy. The association between the total reduction ratio (TRR) of all lesions and liver lesion reduction ratio (LRR) was retrospectively analyzed. A total of 18 patients (47\%) had H3 liver metastases, and the median liver lesion occupancy rate in the sum of the measured lesions with RECIST was $76 \%$. TRR and LRR were strongly correlated, regardless of the volume of the liver metastases. Although a TRR of $>30 \%$ was significantly associated with
\end{abstract}

Correspondence to: Dr Keita Uchino, Department of Medical Oncology, Clinical Research Institute, National Hospital Organization Kyushu Medical Center, 1-8-1 Jigyohama, Chuo-ku, Fukuoka, Fukuoka 810-8563, Japan

E-mail: kuchino-gi@umin.ac.jp

Key words: colorectal cancer, liver metastases, multiple organ metastases, Response Evaluation Criteria In Solid Tumors, liver resection improved overall survival (OS), this improvement was not observed in patients with $\mathrm{H} 3$ liver metastases. TRR was correlated with LRR and was associated with a better OS. CRC patients with both multiple organ and H3 liver metastases exhibited poor survival, even with a high reduction ratio by chemotherapy.

\section{Introduction}

Colorectal cancer (CRC) is the third most common malignancy and the fourth leading cause of cancer-related mortality worldwide $(1,2)$. The improvement in treatments for unresectable advanced or metastatic CRC (mCRC) has markedly changed its prognosis over the past few decades (3-13), and the median overall survival (OS) and progression-free survival (PFS) are currently approaching 30 and 10 months, respectively $(14,15)$. Although PFS has been recognized as a surrogate parameter for OS, the possible effect of post-progression treatments on OS is often considered. A randomized phase 3 trial (First-Line Treatment For Patients With Metastatic Colorectal Cancer-3) examining first-line chemotherapy for mCRC demonstrated that the depth of response (DpR) was correlated with survival time (16). Thus, DpR may also be considered as a surrogate endpoint for OS $(4,16,17)$.

Controlling liver metastases is an important factor for improving OS in CRC patients with limited liver metastases, as several studies have demonstrated that the resection of liver metastases led to a better prognosis compared with hepatectomy after chemotherapy (18-22). In addition, adequate control of extrahepatic lesions is not necessarily associated with favorable survival when liver metastases persist (23). Furthermore, regardless of recurrence in the liver or extrahepatic organs following hepatectomy, hepatectomized patients had a significantly better prognosis compared with patients not undergoing resection (22,24-27). The Japanese Society for Cancer of the Colon and Rectum 2014 guidelines for the treatment of CRC recommend surgical resection of liver metastases when the liver lesions become resectable following 


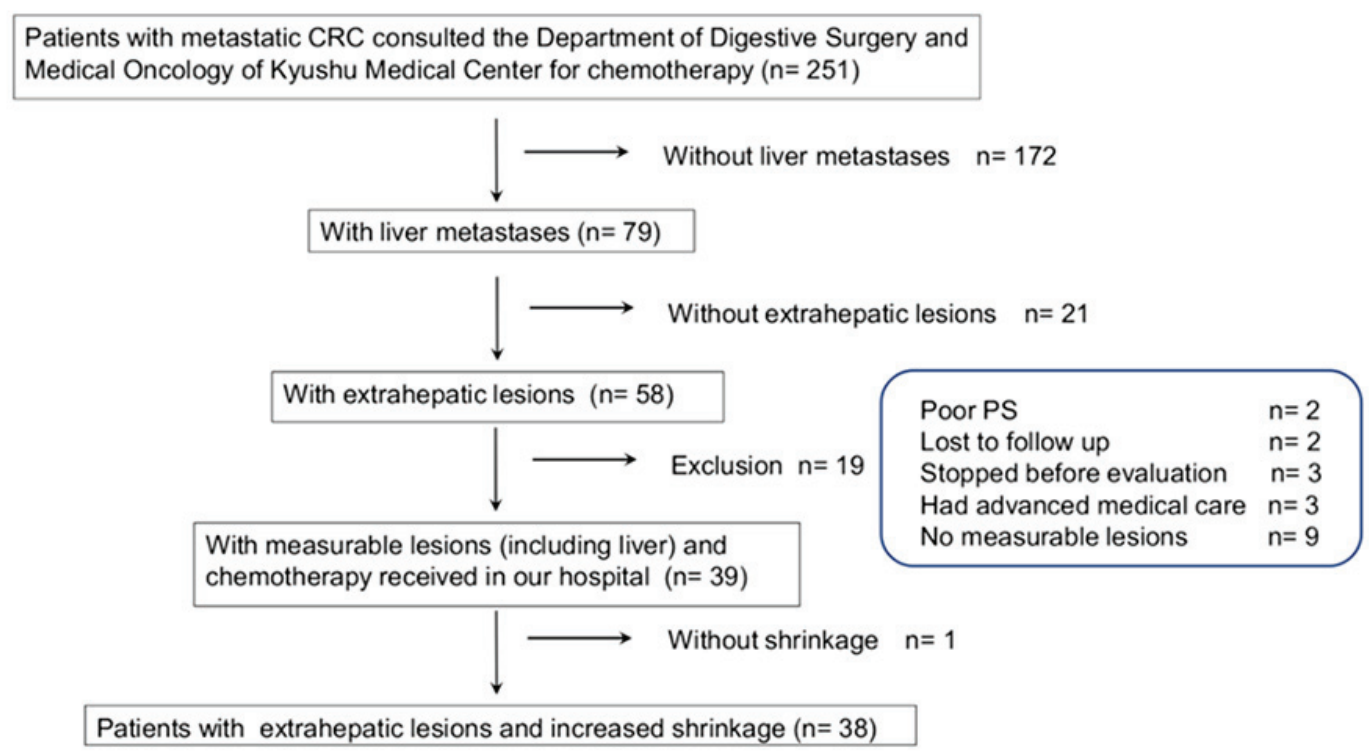

Figure 1. Flowchart of the study population selection process. CRC, colorectal cancer; PS, performance status.

systemic chemotherapy (28-32). However, it remains unknown whether it is also meaningful to control liver metastases by chemotherapy in CRC patients with metastases to multiple organs.

The Response Evaluation Criteria In Solid Tumors (RECIST) has been adopted as a widely accepted method for assessing the objective response of solid tumors to treatment (18). In RECIST version 1.0, the definition of response is a $30 \%$ decrease in the sum of diameters of measurable lesions in up to five organs (18). The number of lesions required to assess tumor burden for response determination was reduced from a maximum of 10 to 5 in the 2009 revision of RECIST guidelines (18), based on evidence that 5 measurable lesions was the minimum number of target lesions that did not cause meaningful changes in the reduction ratio (RR) (33). This revision may provide convenient and reproducible lesion measurements in clinical trials. Assessing the echange in tumor burden is crucial for evaluating tumor response, as both objective tumor response and PFS time are used as endpoints in clinical trials; these parameters are also key to assessing the effectiveness and appropriate selection of treatment in clinical practice. There are no data that analyze the RR for each metastatic organ. Particularly in mCRC, liver metastases are subdivided as H1-H3 according to tumor volume; however, it remains unknown how the degree of shrinkage differs for each case with various tumor volumes of liver metastases.

The aim of the present study was to investigate CRC cases with multiple organ metastases, including the liver, in order to analyze how the TRR is correlated with the LRR and to evaluate whether tumor reduction and the control of liver metastases with systemic chemotherapy can improve patient prognosis.

\section{Patients and methods}

Patients and definition of response. This was a retrospective study on the primary systemic chemotherapy of CRC patients with multiple metastases to the liver and other organs. Between
April 2013 and April 2016, we screened 251 patients with CRC who received consult for the purpose of chemotherapy at the Department of Gastrointestinal Surgery and the Department of Medical Oncology of Kyushu Medical Center Hospital. Among those, 172 patients without liver metastases, 21 patients without extrahepatic lesions and 9 patients without measurable lesions in the liver and extrahepatic organs were excluded. Other patients who were excluded from the analyses were as follows: 2 patients who were unsuitable for chemotherapy due to poor performance status (PS), 2 patients who were lost to follow-up, 3 patients who did not receive chemotherapy prior to the evaluation, 3 patients whose insurance did not cover combined advanced healthcare services, and 1 patient who did not achieve tumor reduction by chemotherapy, as the present study evaluated RR. Finally, 38 patients who had measurable lesions in both the liver and extrahepatic organs, and who were able to continue chemotherapy at our hospital, were analyzed (Fig. 1). Clinical information, including age, sex, Eastern Cooperative Oncology Group PS, RAS mutation status, chemotherapy regimen, primary tumor site, $\mathrm{H}$ stage of liver metastases, tumor RR, treatment duration of primary chemotherapy and survival time, was obtained from medical records. $\mathrm{H}$ stage was determined by the number of liver metastases and size of the largest liver metastatic lesion: H1; $\leq 4$ lesions, and lesions $\leq 5 \mathrm{~cm}$ in diameter, $\mathrm{H} 2$; $\geq 5$ lesions, or lesions $\geq 5 \mathrm{~cm}$ in diameter, and $\mathrm{H} 3$; $\geq 5$ lesions, and lesions $\geq 5 \mathrm{~cm}$ in diameter $(17,34)$. The study protocol was approved by the ethics committee of Kyushu Medical Center Hospital.

The treatment duration of primary chemotherapy was defined as the time from the first day of chemotherapy to the day on which the regimen was changed, or to the date of death from any cause. OS was defined as the time from the first day of chemotherapy to the last day on which the patient was confirmed to be alive, or to the date of death from any cause. For the total lesion reduction ratio (TRR), the selection of measurable lesions and calculation of the RR were conducted according to the RECIST. To evaluate the liver lesions, measurable lesions were selected (up to two lesions in each 
Table I. Clinical characteristics of enrolled patients $(n=38)$.

\begin{tabular}{|c|c|}
\hline Characteristics & Number (\%) \\
\hline \multicolumn{2}{|l|}{ Age, years } \\
\hline$<65$ & $18(47)$ \\
\hline$\geq 65$ & $20(53)$ \\
\hline \multicolumn{2}{|l|}{ Mean 66.2, median 65} \\
\hline \multicolumn{2}{|l|}{ Sex } \\
\hline Male & $18(47)$ \\
\hline Female & $20(53)$ \\
\hline \multicolumn{2}{|l|}{ ECOG-PS } \\
\hline 0 & $18(47)$ \\
\hline 1 & $17(45)$ \\
\hline 2 & $3(8)$ \\
\hline \multicolumn{2}{|l|}{ Primary tumor site } \\
\hline Ascending colon & $10(26)$ \\
\hline Transverse colon & $5(13)$ \\
\hline Descending colon & $1(3)$ \\
\hline Sigmoid colon & $13(34)$ \\
\hline Rectum & $9(24)$ \\
\hline \multicolumn{2}{|l|}{$\mathrm{H}$ stage } \\
\hline H1 & $9(24)$ \\
\hline $\mathrm{H} 2$ & $11(29)$ \\
\hline H3 & $18(47)$ \\
\hline \multicolumn{2}{|l|}{ RAS } \\
\hline Wild-type & $22(58)$ \\
\hline Mutation & $12(32)$ \\
\hline Unknown & 4 \\
\hline \multicolumn{2}{|l|}{ Resection of primary site } \\
\hline Resection & $18(47)$ \\
\hline No resection & $20(53)$ \\
\hline \multicolumn{2}{|l|}{ Liver resection } \\
\hline Resection & $22(58)$ \\
\hline No resection & $16(42)$ \\
\hline \multicolumn{2}{|l|}{ Targeted agents } \\
\hline Bevacizumab & $29(76)$ \\
\hline Anti-EGFR antibody & 0 \\
\hline None & $9(24)$ \\
\hline \multicolumn{2}{|l|}{ Chemotherapy } \\
\hline Two-drug combination & $33(86)$ \\
\hline Single-agent & $5(14)$ \\
\hline \multicolumn{2}{|c|}{ Extrahepatic measurable lesions } \\
\hline Lung & 11 \\
\hline Peritoneum & 5 \\
\hline Lymph nodes & 23 \\
\hline Other & 4 \\
\hline Median liver occupancy & $76 \%(16-94 \%)$ \\
\hline Median OS (days) & 665 (95\% CI: 507.9-822) \\
\hline
\end{tabular}

organ) according to the RECIST, the sum of the major diameters of the hepatic and extrahepatic lesions (short diameter for lymph nodes) was measured, and the reduction ratio at the

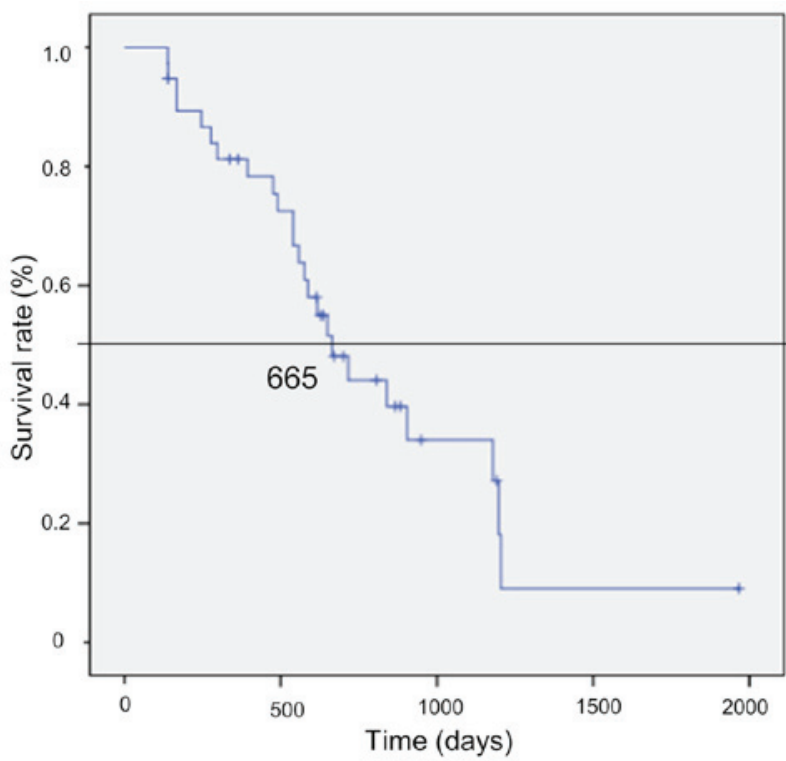

Figure 2. Overall survival of all 38 patients. The median survival time was 22.3 months (95\% confidence interval: 16.9-27.4 months).

time of maximum reduction against pretreatment was calculated. The reduction ratio of all lesions assessed by RECIST was expressed as the TRR and the reduction ratio of only liver lesions was expressed as the liver lesion reduction ratio (LRR). Patients who developed a recurrence following hepatectomy are included in this study. In our hospital, the indications of hepatectomy for each case in which the surgeons consider it technically feasible to resect both the primary tumor and liver metastases, and which can withstand surgery and the disease state is stable, are discussed in a multidisciplinary joint conference.

Statistical analysis. Pearson's correlations were applied to determine the association between TRR and LRR. Partial correlation analysis was used to assess this association controlling for $\mathrm{H}$ stage. Univariate and multivariate analyses of factors associated with OS were calculated with Cox regression survival analysis. OS and duration of primary chemotherapy were calculated with the Kaplan-Meier method, and differences between survival curves were analyzed by the log-rank test. A difference was considered statistically significant when the two-sided P-value was $<0.05$. Patient categorical variables and characteristics between $\mathrm{H} 1 / 2$ and $\mathrm{H} 3$ liver metastases were compared using the Fisher's exact test and Student's t-test, respectively.

\section{Results}

Patient characteristics. The clinical characteristics of the 38 patients who were finally enrolled in this study are listed in Table I. The study population included 18 (47\%) men. The median age at diagnosis was 65 years (range, 44-84 years). The majority of the patients had a PS of 0 or 1 , but the PS of 3 patients was $2(8 \%)$. The primary sites were as follows: 10 cases in the ascending colon $(26 \%), 5$ in the transverse colon (13\%), 1 in the descending colon (3\%), 13 in the sigmoid colon (34\%), and 9 in the rectum (24\%). The RAS status 

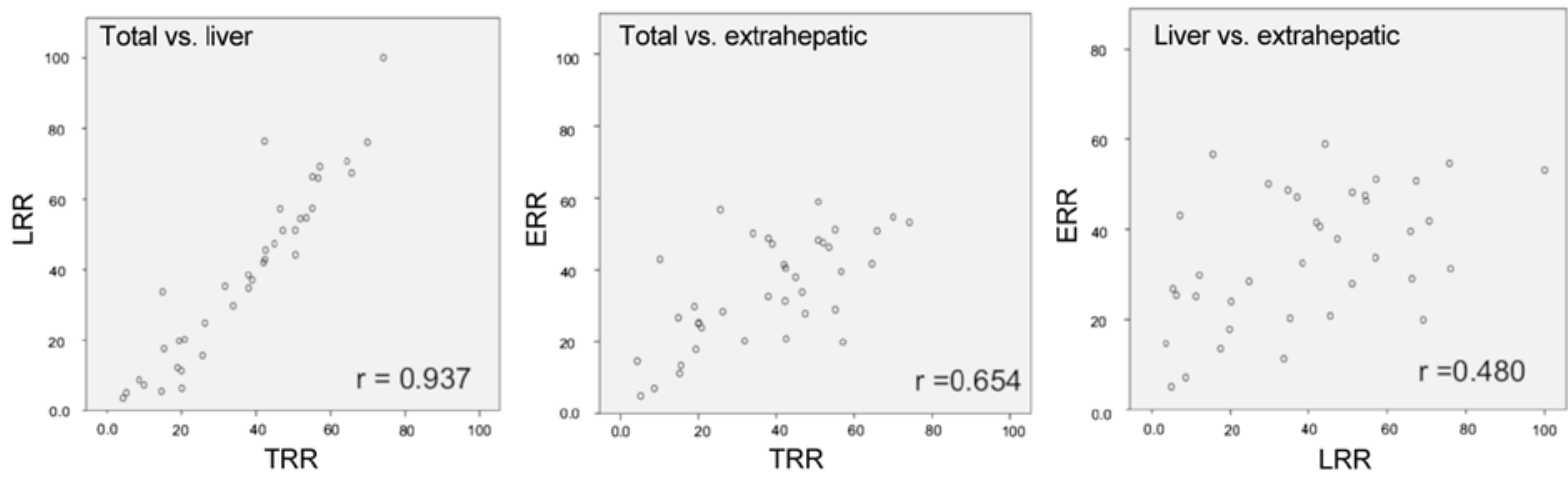

Figure 3. Correlation between total lesion reduction ratio (TRR) and liver lesion reduction ratio (LRR) in all and each $H$ stage of liver metastases (H1/2: $\mathrm{n}=20$, H3: $n=18)$. The mean of the TRR was $37 \%$ (95\% CI: 31-43), and of the LRR 39\% (95\% CI: 31-47). TRR and LRR were strongly correlated in any H stage. ERR, extrahepatic lesions reduction ratio.

was wild-type in 22 patients (29\%), and 4 patients were not investigated. Regarding the $\mathrm{H}$ stage of liver metastases, 9 patients (24\%) were $\mathrm{H} 1,11(27 \%)$ were $\mathrm{H} 2$, and $18(47 \%)$ were H3. Measurable lesions other than those in the liver included lesions in the lung, lymph nodes, peritoneum, ovary, and soft tissue. The median of the maximum diameter of liver lesions was $81.2 \mathrm{~mm}$ (range, 8.39-228.7 $\mathrm{mm}$ ), and the median liver occupancy rate in all measurable lesions of each of the 38 patients was $76 \%$ (range, 16-94\%). Among these patients, 18 underwent resection of the primary site before primary chemotherapy, 11 underwent resection to manage their symptoms, and the remaining 7 underwent radical surgery; 22 of the 38 patients developed recurrence after hepatectomy. A two-drug combination chemotherapy was administered to 33 (86\%) patients, and 29 (76\%) were administered bevacizumab, a molecular-targeted agent. Five patients (14\%) received monotherapy. The median survival time of the 38 patients was 665 days [95\% confidence interval (CI): 548-767] (Fig. 2).

Association between TRR and LRR. The mean of the TRR was $37 \%$ (95\% CI: 31-43), and the mean of the LRR was 39\% (95\% CI: 31-47). TRR and LRR were strongly correlated ( $\mathrm{r}=0.937$, $\mathrm{P}<0.0001)$ in any $\mathrm{H}$ stage (H1/H2: r=0.911, H3: r=0.915; Fig. 3). The results of univariate and multivariate analyses for predictors of OS are summarized in Table II. On univariate analysis, $R A S$ wild-type status, $>30 \%$ of TRR and $>30 \%$ of LRR were associated with a better OS. On multivariate analysis, $R A S$ wild-type status [hazard ratio $(\mathrm{HR})=0.281, \mathrm{P}=0.016$ ] and $>30 \%$ TRR $(\mathrm{HR}=0.23, \mathrm{P}=0.006)$ were independent predictors of better OS.

Association between reduction ratio and OS. Patients with $>30 \%$ TRR had a significantly better OS compared with those with $<30 \%(1,179$ vs. 540 days, respectively; $\mathrm{HR}=0.245,95 \%$ CI: 0.101-0.597, P=0.001) (Fig. 4). Patients with $>30 \%$ LRR also had a significantly better OS compared with those with $<30 \%$ ( 1,179 vs. 540 days, respectively; HR $=0.27,95 \%$ CI: 0.111-0.656, $\mathrm{P}=0.002$ ) (Fig. 5). However, in patients with H3 liver metastases, no significant statistical differences in OS were observed between these two groups of patients upon analysis for each $\mathrm{H}$ stage of liver metastasis ( $\mathrm{H} 1 / 2, \mathrm{HR}=0.225,95 \%$ CI: 0.064-0.791; H3, HR=0.339, 95\% CI: 0.094-1.224) (Fig. 6). The treatment duration of primary chemotherapy in patients

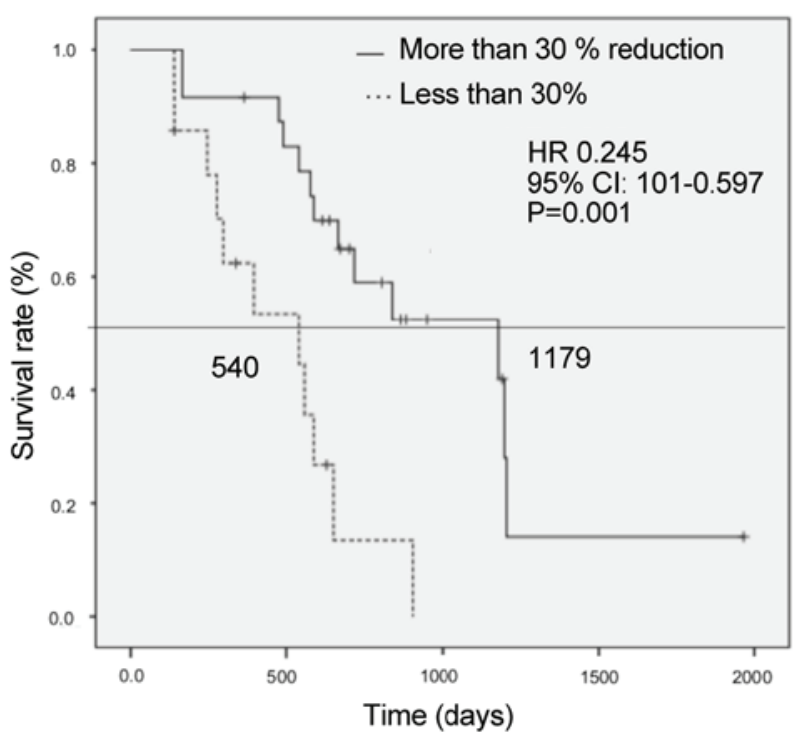

Figure 4. Overall survival (OS) in $>30 \%$ and $<30 \%$ total lesion reduction ratio (TRR). Patients with $>30 \%$ TRR had a significantly better OS compared with those with TRR $<30 \%$. HR, hazard ratio; CI, confidence interval.

with $\mathrm{H} 1 / 2$ liver metastases was significantly longer compared with that in patients with $\mathrm{H} 3$ (389 vs. 250 days, respectively; $\mathrm{HR}=0.472$, 95\% CI: 0.339-0.969, $\mathrm{P}=0.036$ ) (Fig. 7). In comparison to the characteristics of patients with $\mathrm{H} 1 / 2$ and $\mathrm{H} 3$ liver metastases immediately prior to chemotherapy, the maximum diameter of liver metastases, number of liver metastases, and levels of serum carcinoembryonic antigen, serum cancer antigen 19-9, aspartate transaminase, lactate dehydrogenase, alkaline phosphatase and $\gamma$-glutamyl transpeptidase, were higher in $\mathrm{H} 3$ patients. On the other hand, the serum albumin levels were higher in $\mathrm{H} 1 / 2$ patients. Furthermore, more patients with $R A S$ mutations were $\mathrm{H} 3$ (Table III).

\section{Discussion}

To the best of our knowledge, this was the first study to investigate the correlation between RECIST RR and the LRR in mCRC patients, and to analyze the association between tumor reduction of liver metastases and prognosis. A strong correlation between TRR and LRR in any $H$ stage was 
Table II. Univariate and multivariate analyses for predictors of overall survival.

\begin{tabular}{|c|c|c|c|c|}
\hline \multirow[b]{2}{*}{ Variables } & \multirow{2}{*}{$\frac{\text { Univariate }}{\text { P-value }}$} & \multicolumn{3}{|c|}{ Multivariate } \\
\hline & & HR & $95 \%$ CI & P-value \\
\hline $\begin{array}{l}\text { Age, years } \\
\geq 65 \text { vs. }<65\end{array}$ & 0.517 & & & \\
\hline $\begin{array}{l}\text { Sex } \\
\text { Male vs. female }\end{array}$ & 0.517 & & & \\
\hline $\begin{array}{l}\text { ECOG PS score } \\
0-1 \text { vs. } 2-4\end{array}$ & 0.333 & & & \\
\hline $\begin{array}{l}\text { Liver metastases time } \\
\text { Synchronous vs. metachronous }\end{array}$ & 0.451 & & & \\
\hline $\begin{array}{l}\text { Resection of primary site } \\
\text { Resection vs. no resection }\end{array}$ & 0.265 & & & \\
\hline $\begin{array}{l}\text { H stage of liver metastases } \\
\mathrm{H} 1 \text { or } 2 \text { vs. H3 }\end{array}$ & 0.118 & & & \\
\hline $\begin{array}{l}\text { RAS status } \\
\text { Wild-type vs. mutation }\end{array}$ & 0.041 & 0.016 & 0.281 & $0.100-0.786$ \\
\hline $\begin{array}{l}\text { CEA level } \\
\text { High vs. normal }\end{array}$ & 0.539 & & & \\
\hline $\begin{array}{l}\text { CA19-9 level } \\
\text { High vs. normal }\end{array}$ & 0.246 & & & \\
\hline $\begin{array}{l}\text { RECIST RR } \\
\geq 30 \text { vs. }<30 \%\end{array}$ & 0.002 & 0.006 & 0.238 & $0.086-0.657$ \\
\hline $\begin{array}{l}\text { Liver RR } \\
\geq 30 \text { vs. }<30 \%\end{array}$ & 0.004 & $(0.024)$ & $(0.35)$ & $(0.141-0.871)$ \\
\hline $\begin{array}{l}\text { RR other than liver } \\
\geq 30 \text { vs. }<30 \%\end{array}$ & 0.012 & & & \\
\hline $\begin{array}{l}\text { No. of liver metastases } \\
\geq 5 \text { vs. }<5\end{array}$ & 0.327 & & & \\
\hline $\begin{array}{l}\text { Primary site } \\
\text { Right vs. left colon }\end{array}$ & 0.848 & & & \\
\hline $\begin{array}{l}\text { Albumin level } \\
\text { Low vs. normal }\end{array}$ & 0.855 & & & \\
\hline $\begin{array}{l}\text { Targeted agents } \\
\text { Yes vs. no }\end{array}$ & 0.158 & & & \\
\hline
\end{tabular}

HR, hazard ratio; CI, confidence interval; ECOG PS, Eastern Cooperative Oncology Group performance status; CEA, carcinoembryonic antigen; CA, carbohydrate antigen; RECIST, Response Evaluation Criteria in Solid Tumors; RR, reduction ratio.

observed. In mCRC cases with liver metastases, regardless of the tumor volume of the liver ( $\mathrm{H}$ stage), the TRR reflected the LRR (Fig. 3). As 70-87\% of patients with unresectable or recurrent CRC harbored liver metastases $(32,33,35-38)$, the $\mathrm{RR}$ reported in clinical trials for unresectable or recurrent CRC mostly reflected the LRR.

In the present study, no patients received anti-epidermal growth factor receptor (EGFR) antibody, and only bevacizumab was used as a molecular-targeted agent. It was reported that anti-EGFR antibody combination therapy exerted a higher tumor shrinkage effect compared with anti-vascular endothelial growth factor combination antibodies (35-37). These cases, even in patients with wild-type $R A S$, did not require an immediate reduction effect, but rather a sustained treatment strategy of sequential therapies.

Multivariate analysis revealed that $>30 \%$ tumor reduction was correlated with a favorable prognosis. The OS was significantly better in patients with $>30 \%$ reduction ratio in the log-rank test (Figs. 4 and 5), and DpR was suggested to improve the prognosis. However, in the analysis of the association between reduction of liver metastases and prognosis of each $\mathrm{H}$ stage, no statistically significant difference 

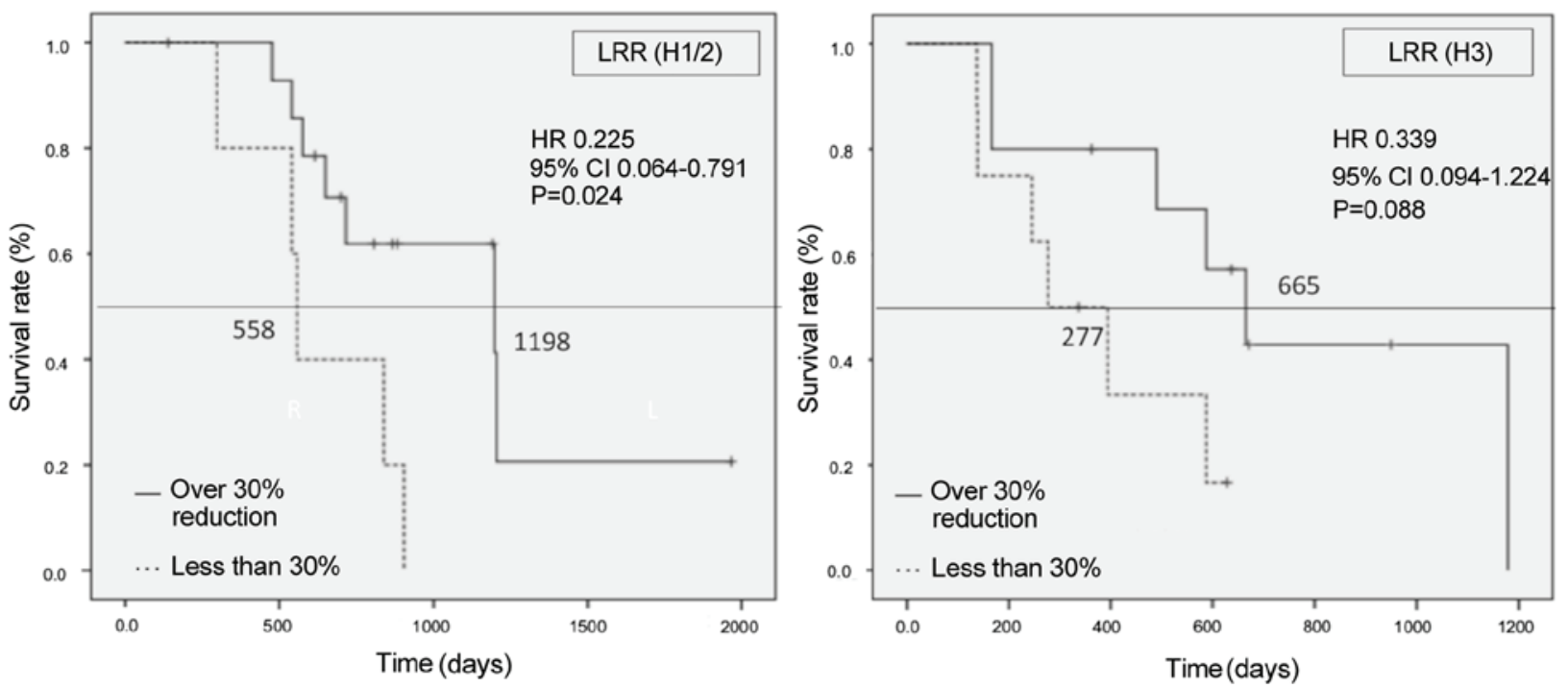

Figure 5. Overall survival (OS) in $>30 \%$ and $<30 \%$ liver lesion reduction ratio (LRR). Patients with $>30 \%$ LRR also had a significantly better OS compared with those with LRR $<30 \%$. HR, hazard ratio; CI, confidence interval.
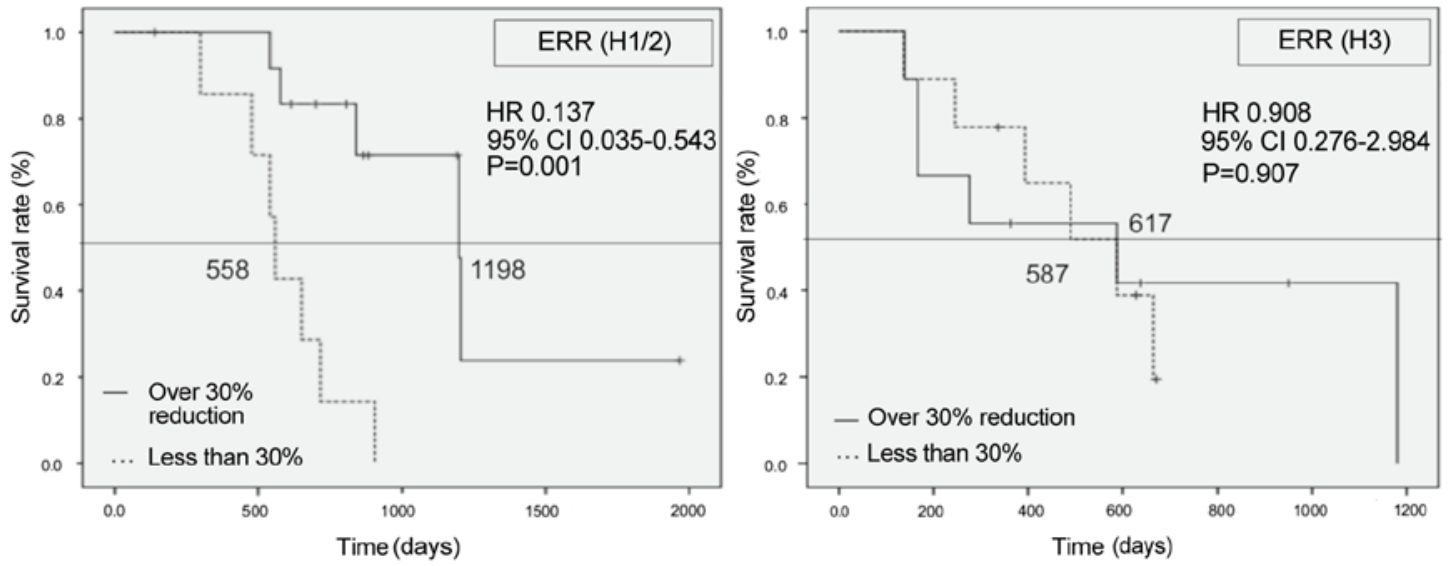

Figure 6. Overall survival (OS) in patients with $>30 \%$ liver lesion reduction ratio (LRR) when stratified according to $\mathrm{H}$ stage. In patients with $\mathrm{H} 3$ liver metastases, no statistically significant differences in OS were observed between these two groups of patients upon analysis for each $\mathrm{H}$ stage of liver metastasis. HR, hazard ratio; CI, confidence interval; ERR, extrahepatic lesions reduction ratio.

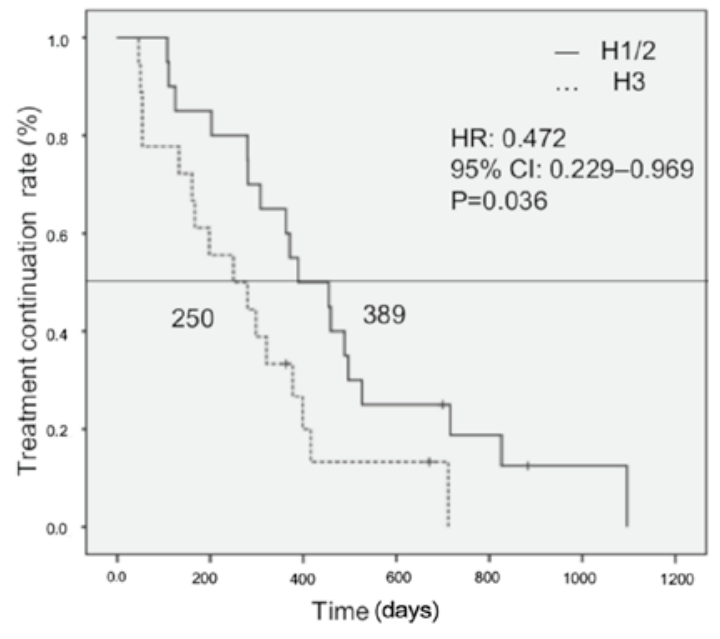

Figure 7. Primary treatment duration of patients with H1/2 and H3 liver metastases. The treatment duration of primary chemotherapy in patients with H1/2 liver metastases was significantly longer compared with that in patients with H3. HR, hazard ratio; CI, confidence interval. was observed in patients with $\mathrm{H} 3$ liver metastases, even with $>30 \%$ reduction of the lesions (Fig. 6). Although there may not be a significant difference due to the small number of cases, it is suggested there are some factors that affect the prognosis in addition to tumor reduction in the $\mathrm{H} 3$ group.

In the $\mathrm{H} 3$ group, the duration of primary chemotherapy was clearly shorter compared with the H1/2 group. Liver function prior to treatment of $\mathrm{H} 3$ patients was significantly worse compared with that of H1/2 patients (Table III), but there was no difference in the dose intensity and treatment intensity of chemotherapy. Considering the rapid regrowth of lesions and appearance of new lesions in the $\mathrm{H} 3$ group, the poor prognosis may be attributed to the biological characteristics of the tumor. An example is the $R A S$ mutation. In this study, $R A S$ mutation was a contributing factor to the poor prognosis on multivariate analysis $(\mathrm{HR}=3.5, \mathrm{P}=0.02$; Table II), and more patients in the $\mathrm{H} 3$ group tended to harbor $R A S$ mutations, although the difference was not statistically significant. Several studies have 
Table III. Comparison of characteristics between H1/2 and $\mathrm{H} 3$ liver metastases.

\begin{tabular}{|c|c|c|c|}
\hline Characteristics & $\mathrm{H} 1 / \mathrm{H} 2(\mathrm{n}=20)$ & H3 $(n=18)$ & P-value \\
\hline PS score & & & 0.594 \\
\hline $0-1$ & $19(95)$ & $16(89)$ & \\
\hline 2 & $1(5)$ & $2(11)$ & \\
\hline Age, years & & & 0.531 \\
\hline$<65$ & $10(50)$ & $7(39)$ & \\
\hline$\geq 65$ & $10(50)$ & $11(61)$ & \\
\hline Sex & & & 0.351 \\
\hline Male & $11(55)$ & $7(39)$ & \\
\hline Female & $9(45)$ & $11(61)$ & \\
\hline Liver metastases & & & 0.72 \\
\hline Synchronous & $14(70)$ & $18(100)$ & \\
\hline Metachronous & $6(30)$ & $0(0)$ & \\
\hline Targeted drug & & & 0.13 \\
\hline Yes & $13(65)$ & $16(89)$ & \\
\hline No & $7(35)$ & $2(11)$ & \\
\hline Shrinkage & & & 0.503 \\
\hline$\geq 30 \%$ & $14(70)$ & $10(56)$ & \\
\hline$<30 \%$ & $6(30)$ & $8(44)$ & \\
\hline Pathology & & & 1.00 \\
\hline Tubular & $6(30)$ & $6(33)$ & \\
\hline Others & $14(70)$ & $12(67)$ & \\
\hline Primary site & & & 0.468 \\
\hline Colon & $16(80)$ & $12(67)$ & \\
\hline Rectum & $4(20)$ & $6(33)$ & \\
\hline Resection of primary site & & & 0.058 \\
\hline Resection & $12(60)$ & $5(28)$ & \\
\hline No resection & $8(40)$ & $13(72)$ & \\
\hline Number of liver metastases & & & 0.025 \\
\hline$\geq 6$ & $8(40)$ & $14(78)$ & \\
\hline$<6$ & $12(60)$ & $4(22)$ & \\
\hline RAS status & & & 0.089 \\
\hline Wild-type & $14(70)$ & 7 (39) & \\
\hline Mutation & $5(25)$ & $10(61)$ & \\
\hline Unknown & 1 & 1 & \\
\hline Maximum diameter of hepatic metastases (mm) & $29.45(8.39-54.79)$ & $29.45(8.39-54.79)$ & $<0.001$ \\
\hline $\mathrm{CEA}(\mathrm{ng} / \mathrm{ml})$ & $13.5(6.2-1,314.5)$ & $221.1(4.3-1,471.1)$ & 0.045 \\
\hline CA19-9 (U/ml) & $12(1-2,937)$ & $873(4.1-10,590)$ & 0.0007 \\
\hline $\operatorname{AST}(\mathrm{U} / \mathrm{ml})$ & $20(12-85)$ & $39(14-210)$ & 0.011 \\
\hline ALT (U/ml) & $19(10-62)$ & $25.5(8-85)$ & 0.41 \\
\hline LDH (U/ml) & $225(141-406)$ & $415(175-2,400)$ & 0.0076 \\
\hline ALP (U/ml) & $244(141-815)$ & $462(7-1,291)$ & $<0.001$ \\
\hline$\gamma$-GTP $(\mathrm{U} / \mathrm{ml})$ & $31(13-255)$ & $109.5(24-495)$ & 0.023 \\
\hline Serum albumin $(\mathrm{g} / \mathrm{dl})$ & $3.7(2.6-4.6)$ & $3.2(2.0-4.0)$ & 0.012 \\
\hline Lymph node metastases & & & 1.00 \\
\hline Yes & $10(50)$ & $9(50)$ & \\
\hline No & $10(50)$ & $9(50)$ & \\
\hline
\end{tabular}

Data are presented as no. (\%) or as median (range). PS, performance status; CEA, carcinoembryonic antigen; CA19-9, carbohydrate antigen 19-9; AST, aspartate transaminase; ALT, alanine transaminase; LDH, lactate dehydrogenase; ALP, alkaline phosphatase; $\gamma$ GTP, $\gamma$-glutamyltransferase 
reported that mutations in the $R A S$ gene itself is a poor prognostic factor (38-42), and that prognosis following hepatectomy is poor in the $R A S$ mutation group. Thus, mutations in the $R A S$ gene may lead to an aggressive tumor phenotype (43-45). Although $B R A F$ mutations were not examined in this study, further progress in gene research is expected to provide more detailed prognostic predictions and treatment strategies.

These results suggest that $>30 \%$ reduction did not always improve the prognosis in CRC patients with $\mathrm{H} 3$ liver metastasis. For such cases, systemic chemotherapy alone may not improve the prognosis, and other treatment strategies may be required to control liver metastases, such as combination with local treatment, including debulking liver resection. There are some reports that liver metastasis control contributes to the improvement of survival. For example, Elias et al (24) reported that the prognosis was improved by curative resection of liver lesions, even if the patients had extrahepatic metastases, and Bokemeyer et al (41) reported that a good prognosis was obtained by combining resection with chemotherapy, even with R1 resection of liver metastases. However, Passot et al (40) reported that node-positive primary tumors, a tumor diameter of $>3 \mathrm{~cm}$, and $>7$ cycles of preoperative chemotherapy, were factors associated with worse OS for mCRC patients who had hepatectomy, and the more of these prognostic factors the patients had, the worse their OS, even if R0 hepatectomy was performed. Maughan et al (42) reported that the response to preoperative chemotherapy was likely to be a significant prognostic factor affecting survival time following curative hepatectomy. Therefore, it is hypothesized that the prognosis after hepatectomy may be associated with various factors, and further studies on the therapeutic indications for local control of liver metastases are needed.

There were certain limitations to the present study. First, this was a retrospective single-center study, and the number of cases was limited. Second, recurrence cases after hepatectomy are included, whereas time to relapse was not considered. Third, the treatment regimen was not uniform. Fourth, tumor reduction was evaluated only by the tumor diameter, and the possible reduction effect of changes such as tumor necrosis and lumen formation could not be evaluated in this manner.

It may be that larger tumors are less likely to exhibit shrinkage due to tumor necrosis and lumen formation; therapeutic effect evaluation may be difficult in these cases.

Taken together, the results of the present study demonstrated that the LRR was strongly reflected by the TRR in mCRC cases with liver metastases. The correlation of DpR with both TRR and LRR and prognosis was suggested; however, $\mathrm{H} 3$ patients did not achieve prolonged survival, even in DpR cases. Multidisciplinary treatments, including local therapy, may improve the prognosis of $\mathrm{H} 3$ patients. However, further studies with a larger number of cases are needed to draw more definitive conclusions.

\section{Acknowledgements}

Not applicable.

\section{Funding}

No funding was received.

\section{Availability of data and materials}

All the datasets generated and analyzed in the present study are included in this published manuscript.

\section{Authors' contributions}

SK and KU conceived the present study. SK designed the current study and performed the necessary calculations. SK, $\mathrm{KU}$ and $\mathrm{MN}$ verified the analytical methods used. $\mathrm{EB}$ and $\mathrm{KU}$ performed the experiments. All authors discussed the results and contributed to the final manuscript.

\section{Ethics approval and consent to participate}

The study protocol was approved by the Ethics Committee of Kyushu Medical Center Hospital.

\section{Patient consent for publication}

Not applicable.

\section{Competing interests}

The authors declare that they have no competing interests.

\section{References}

1. Jemal A, Bray F, Center MM, Ferlay J, Ward E and Forman D: Global cancer statistics. CA Cancer J Clin 61: 69-90, 2011.

2. Ferlay J, Shin HR, Bray F, Forman D, Mathers C and Parkin DM: Estimates of Worldwide burden of cancer in 2008: GLOBOCAN 2008. Int J Cancer 127: 2893-2917, 2010.

3. Manfredi S, Lepage C, Hatem C, Coatmeur O, Faivre J and Bouvier AM: Epidemiology and management of liver metastases from colorectal cancer. Ann Surge 244: 254-259, 2006.

4. Heinemann V, Stintzing S, Modest DP, Giessen-Jung C, Michl M and Mansmann UR: Early tumor shrinkage (ETS) and depth of response $(\mathrm{DpR})$ in the treatment of patients with metastatic colorectal cancer (mCRC). Eur J Cancer 51: 1927-1936, 2015.

5. Schmoll HJ, Van Cutsem E, Stein A, Valentini V, Glimelius B, Haustermans K, Nordlinger B, van de Velde CJ, Balmana J, Regula J, et al: ESMO consensus guidelines for management of patients with colon and rectal cancer. A personalized approach to clinical decision making. Ann Oncol 23: 2479-2516, 2012.

6. Van Cutsem E, Dicato M, Arber N, Berlin J, Cervantes A, Ciardiello F, De Gramont A, Diaz-Rubio E, Ducreux M, Geva R, et al: Molecular markers and biological targeted in metastasis colorectal cancer: Expert opinion and recommendations derived from the 11th ESNO/World Congress on Gastrointestinal Cancer, Barcelona, 2009. Ann Oncol 21 (Suppl 6): vi1-10, 2010.

7. Ye LC, Liu TS, Ren L, Wei Y, Zhu DX, Zai SY, Ye QH, Yu Y, $\mathrm{Xu}$ B, Qin XY and Xu J: Randomized controlled trial of cetuximab plus chemotherapy for patients with LRAS wild-type unresectable colorectal liver-limited metastases. J Clin Oncol 31: 1931-1938, 2013.

8. Folprecht G, Gruenberger T, Bechstein WO, Raab HR, Lordick F, Hartmann JT, Lang H, Frilling A, Stoehlmacher J, Weitz J, et al: Tumor response and secondary resectability of colorectal liver metastases following neoadjuvant chemotherapy with cetuximab: The CELIM randomized phase II trial. Lancet Oncol 11: 38-47, 2010.

9. Van Cutsem E, Köhne CH, Hitre E, Zaluski J, Chang Chien CR, Makhson A, D'Haens G, Pintér T, Lim R, Bodoky G, et al: Cetuximab and chemotherapy as initial treatment for metastatic colorectal cancer. N Engl J Med 360: 1408-1417, 2009.

10. Bokemeyer C, Bondarenko I, Makhson A, Hartmann JT, Aparicio J, de Braud F, Donea S, Ludwig H, Schuch G, Stroh C, et al: Fluororacil, leucovorin, and oxaliplatin with and without cetuximab in the first line treatment of metastatic colorectal cancer. J Clin Oncol 27: 663-671, 2009. 
11. Saltz LB, Clarke S, Díaz-Rubio E, Scheithauer W, Figer A, Wong R, Koski S, Lichinitser M, Yang TS, Rivera F, et al: Bevacizumab in combination with oxaliplatin-based chemotherapy as first-line therapy in metastatic colorectal cancer: A randomized phase III study. J Clin Oncol 26: 2013-2019, 2008.

12. Douillard JY, Oliner KS, Siena S, Tabernero J, Burkes R, Barugel M, Humblet Y, Bodoky G, Cunningham D, Jassem J, et al: Panitumumab-FOLFOX4 treatment and RAS mutations in colorectal cancer. N Engl J Med 369: 1023-1034, 2013.

13. Hurwitz H, Fehrenbacher L, Novotny W, Cartwright $T$, Hainsworth J, Heim W, Berlin J, Baron A, Griffing S Holmgren E, et al: Bevacizumab plus irinotecan, fluoriuracil, and leucovolin for metastatic colorectal cancer. N Engl J Med 350: 2335-2342, 2004.

14. Fakih MG: Metastatic colorectal cancer: Current state and future directions. J Clin Oncol 33: 1809-1824, 2015.

15. Heinemann V, von Weikersthal LF, Decker T, Kiani A, Vehling-Kaiser U, Al-Batran SE, Heintges T, Lerchenmüller C, Kahl C, Seipelt G, et al: FOLFIRI plus cetuximab versus FOLFIRI plus bevacizumab as first-line treatment for patients with metastatic colorectal cancer (FIRE-3): A randomized, open-label, phase III trial. Lancet Oncol 15: 1065-1075, 2014.

16. Osumi H, Matsusaka S, Suenaga M, Wakatsuki T, Ogura M, Ozaka M, Shinozaki E, Chin K and Mizunuma N: Quantitative analysis of the impact of deepness of response on survival time following patients with metastatic colorectal cancer treated by chemotherapy and anti-EGFR monoclonal antibodies. J Clin Oncol 32 (3 Suppl): S493, 2014.

17. Peeters M, Price TJ, Cervantes A, Sobrero A, Ducreux MP, André T, Lordick F, Punt CJA, Koukakis R, Terwey J and van Custem E: Tumour shrinkage and response outcomes during second-line panitumumab (pmab) + FOLFIRI vs FOLFIRI treatment. Ann Oncol 25 (Suppl 4): iv186-iv187, 2014.

18. Eisenhauer EA, Therasse P, Bogaerts J, Schwartz LH, Sargent D, Ford R, Dancey J, Arbuck S, Gwyther S, Mooney M, et al: New response evaluation criteria in solid tumours: Revised RECIST guideline (version 1.1). Eur J Cancer 45: 228-247, 2009.

19. Nordlinger B, Van Cutsem E, Gruenberger T, Glimelius B, Poston G, Rougier P, Sobrero A and Ychou M; European Colorectal Metastases Treatment Group; Sixth International Colorectal Liver Metastases Workshop: Combination of surgery and chemotherapy and the role of targeted agents in the treatment of patients with colorectal liver metastases: Recommendations from an expert panel. Ann Oncol 20: 985-992, 2009.

20. Adam R, Lucidi V and Bismuth H: Hepatic colorectal metastases: Methods of improving resectability. Surge Clin North Am 84: 659-671, 2004

21. Pawlik TM and Choti MA: Surgical therapy for colorectal metastases to the liver. J Gastrointest Surg 11: 1057-1077, 2007.

22. Sharma S, Camci C and Jobbour N: Management of hepatic metastasis from colorectal cancers: An update. J Hepatobiliary Pancreat Surg 15: 570-580, 2008.

23. Himuro N, Minakata T, Oshima Y, Kataoka D, Yamamoto S and Kadokura M: Prognostic indicators after resection of pulmonary metastases from colon and rectal cancer. J Jpn Assoc Chest Surg 30: 136-142, 2016.

24. Elias D, Sideris L, Pocard M, Ouellet JF, Boige V, Lasser P, Pignon JP and Ducreux M: Results of R0 resection for colorectal liver metastases associated with extrahepatic disease. Ann Surg Oncol 11: 274-280, 2004

25. Adam R, de Gramont A, Figueras J, Kokudo N, Kunstlinger F, Loyer E, Poston G, Rougier P, Rubbia-Brandt L, Sobrero A, et al: Managing synchronous liver metastases from colorectal cancer: A multidisciplinary international consensus. Cancer Treat Rev 41: 729-741, 2015

26. Yoshidome H, kimura F, Shimizu H, Ohysuka M and Miyazaki M: Advances in surgical treatment for colorectal liver metastases. Nippon Shokakibyo Gakkai Zasshi 106: 1438-1446, 2009 (In Japanese).

27. Yang YY, Fleshman JW and Strasberg SM: Detection and management of extrahepatic colorectal cancer in patients with resectable liver metastases. J Gastrointest Surg 11: 929-944, 2007.

28. Adam R: Developing strategies for liver metastases from colorectal cancer. Semin Oncol Apr 34 (2 Suppl 1): S7-S11, 2007.

29. Lam VW, Spiro C,Laurence JM,Johnston E, Hollands MJ,Pleass HC and Richardson AJ: A systematic review of clinical response and survival outcomes of downsizing systemic chemotherapy and rescue liver surgery in patients with initially unresectable colorectal liver metastases. Ann Surg Oncol 19: 1292-1301, 2012.
30. Watanabe T, Itabashi M, Shimada Y, Tanaka S, Ito Y, Ajioka Y, Hamaguchi T, Hyodo I, Igarashi M, Ishida H, et al: Japanese society for cancer of the colon and rectum (JSCCR) guidelines 2014 for treatment of colorectal cancer. Int J Clin Oncol 20: 207-239, 2015.

31. Borner MM: Neoadjuvant chemotherapy for unresectable liver metastases of colorectal cancer-too good to be true? Ann Oncol 10: 623-626, 1999.

32. Cummings LC, Payes JD and Cooper GS: Survival after hepatic resection in metastatic colorectal cancer: A population-based study. Cancer 109: 718-726, 2007.

33. Bogaerts J, Ford R, Sargent D, Schwartz LH, Rubinstein L, Lacombe D, Eisenhauer E, Verweij J and Therasse P; RECIST Working Party: Individual patient data analysis to assess modifications to the RECIST criteria. Eur J Cancer 45: 248-260, 2009.

34. Yamaguchi T, Mori T, Takahashi K, Matsumoto H, Miyamoto H and Kato T: A new classification system for liver metastases from colorectal cancer in Japanese multicenter analysis. Hepatogastroenterology 55: 173-178, 2008.

35. Cassidy J, Clarke S, Díaz-Rubio E, Scheithauer W, Figer A, Wong R, Koski S, Lichinitser M, Yang TS, Rivera F, et al: Randomized phase III study of capecitabine plus oxaliplatin compared with fluorouracil/folinic acid plus oxaliplatin as first-line therapy for metastatic colorectal cancer. J Clin Oncol 26: 2006-2012, 2008

36. Klinger M, Tamandl D, Eipeldauer S, Hacker S, Herberger B, Kaczirek K, Dorfmeister M, Gruenberger B and Gruenberger T: Bevacizumab improves pathological response of colorectal cancer liver metastases treated with XELOX/FOLFOX. Ann Surge Oncol 17: 2059-2065, 2010.

37. Zorzi D, Chun YS, Madoff DC, Abdalla EK and Vauthey JN: Chemotherapy with bevacizumab does not affect liver regeneration after portal vein embolization in the treatment of colorectal liver metastases. Ann Surg Oncol 15: 2765-2772, 2008.

38. Veen T and Søreide K: Can molecular biomarkers replace a clinical risk score for resectable colorectal liver metastasis? World J Gastrointest Oncol 9: 98-104, 2017.

39. Brudvik KW, Kopetz SE, Li L, Conrad C, Aloia TA and Vauthey JN: Meta-analysis of KRAS mutations and survival after resection of colorectal liver metastases. Br J Surg 102: 1175-1183, 2015.

40. Passot G, Denbo JW, Yamashita S, Kopetz SE, Chun YS, Maru D Overman MJ, Brudvik KW, Conrad C, Aloia TA and Vauthey JN: Is Hepatectomy justified for Patients with RAS mutant colorectal liver metastases? An analysis of 524 patients undergoing curative liver resection. Surgery 161: 332-340, 2017.

41. Bokemeyer C, Kohne C, Rougier P, Stroh C, Schlichting M and Van Cutsem E: Cetuximab with chemotherapy (CT) as first-line treatment for metastatic colorectal cancer (mCRC): Analysis of the CRYSTAL and OPUS studies according to KRAS and BRAF mutation status. (ASCO Annual Meeting, abstract no. 3506). J Clin Oncol 28: 15s, 2010.

42. Maughan TS, Adams RA, Smith CG, Meade AM, Seymour MT, Wilson RH, Idziaszczyk S, Harris R, Fisher D, Kenny SL, et al: Addition of cetuximab to oxaliplatin-based first-line combination chemotherapy for treatment of advanced colorectal cancer: Results of the randamised phase 3 MRC COIN trial. Lancet 377: 2103-2114, 2011

43. Odisio BC, Yamashita S, Huang SY, Harmoush S, Kopetz SE, Ahrar K, Shin Chun Y, Conrad C, Aloia TA, Gupta S, et al: Local tumour progression after percutaneous ablation of colorectal liver metastases according to RAS mutation status. Br J Surge 104 760-768, 2017.

44. Vauthey JN, Zimmitti G, Kopetz SE, Shindoh J, Chen SS, Andreou A, Curley SA, Aloia TA and Maru DM: RAS mutation status predicts survival and patterns of recurrence in patients undergoing hepatectomy for colorectal liver metastases. Ann Surg 258: 619-626; discussion 626-627, 2013

45. Margonis GA, Kim Y, Spolverato G, Ejaz A, Gupta R, Cosgrove D, Anders R, Karagkounis G, Choti MA, Pawlik TM, et al: Association between specific mutations in KRAS Codon 12 and colorectal liver metastasis. JAMA Surg 150: 722-729, 2015.

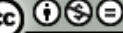

This work is licensed under a Creative Commons Attribution-NonCommercial-NoDerivatives 4.0 International (CC BY-NC-ND 4.0) License. 